\title{
Sleep duration and risk of obesity among a sample of Victorian school children
}

\author{
Bridget Morrissey ${ }^{1 *}$, Mary Malakellis ${ }^{2}$, Jill Whelan ${ }^{3}$, Lynne Millar ${ }^{1,2}$, Boyd Swinburn ${ }^{2,4}$, Steven Allender ${ }^{1,2}$ \\ and Claudia Strugnell ${ }^{2}$
}

\begin{abstract}
Background: Insufficient sleep is potentially an important modifiable risk factor for obesity and poor physical activity and sedentary behaviours among children. However, inconsistencies across studies highlight the need for more objective measures. This paper examines the relationship between sleep duration and objectively measured physical activity, sedentary time and weight status, among a sample of Victorian Primary School children.

Methods: A sub-sample of 298 grades four $(n=157)$ and six $(n=132)$ Victorian primary school children (aged 9.2-13.2 years) with complete accelerometry and anthropometry data, from 39 schools, were taken from a pilot study of a larger state based cluster randomized control trial in 2013. Data comprised: researcher measured height and weight; accelerometry derived physical activity and sedentary time; and self-reported sleep duration and hypothesised confounding factors (e.g. age, gender and environmental factors).

Results: Compared with sufficient sleepers (67\%), those with insufficient sleep ( $<10$ hrs/day) were significantly more likely to be overweight (OR 1.97, 95 \% Cl:1.11-3.48) or obese (OR 2.43, 95 \% Cl:1.26-4.71). No association between sleep and objectively measured physical activity levels or sedentary time was found.

Conclusion: The strong positive relationship between weight status and sleep deprivation merits further research though PA and sedentary time do not seem to be involved in the relationship. Strategies to improve sleep duration may help obesity prevention initiatives in the future.
\end{abstract}

Keywords: Sleep, Sleep duration, Children, School children, Overweight, Obesity, Accelerometry, ActiGraph, Physical activity, Sedentary behaviour

\section{Background}

The underlying determinants of childhood overweight and obesity have been the subject of much research globally $[1,2]$ and it has been established that physical activity (PA), sedentary time (ST) and dietary intake are key modifiable risk factors [2-5]. Recent thinking suggests a widening of the range of potential modifiable factors to consider the association of insufficient sleep [2, 6, 7]. Findings from recent studies indicate that children who sleep for insufficient durations $(<10 \mathrm{hrs})$ are more likely to exhibit higher Body Mass Index (BMI), waist circumference (WC) and obesity rates $[8-10]$.

\footnotetext{
* Correspondence: bridget.morrissey@deakin.edu.au

${ }^{1}$ School of Health and Social Development, Deakin University, 221 Burwood Hwy, Burwood, Victoria 3125, Australia

Full list of author information is available at the end of the article
}

While some variation in recommendations exist, it is commonly accepted that children aged five to 12 years receive between 9 and 11 hours of sleep per night [11, 12]. Internationally average sleep durations have been decreasing over recent decades [13]. Australian data has reported a decline in average sleep durations of approximately 28 mins and 33 mins (for girls and boys respectively) among Australian children between 1985 and 2004 [14]. The global trend in decreasing sleep has occurred at the same time as increases in the prevalence of overweight and obesity [13-15]. These trends are supported by studies that found insufficient sleep among children was associated with an increased risk of overweight and obesity [16-19], reduced physical activity and increased sedentary behaviours $[9,16,17]$. Children's increased screen time and use of electronic devices around bedtime has also been theorised as a potential link to these trends [19]. 
A reoccurring issue of available literature on children's sleep, weight status PA and SB is the predominant utilisation of subjective measures $[14,17]$. While some studies have incorporated objective measures, some findings are conflicting and inconsistencies in measurement methods make comparison of results difficult [20]. Findings from two studies utilising wrist-worn accelerometers [21, 22] and one using hip-worn accelerometry [23] to objectively measure children's activity have contrasted greatly. Gupta et al. (2002) reported that poor sleep over a 24 hour period lead to significant reductions in next day PA [22], while Eskedt et al. (2013) reported no significant association between sleep duration and PA levels over a 7 day period [21]. Contradicting both of these studies, hip-worn accelerometry data from Nixon et al. (2008) found that higher levels of daytime activity were associated with reduced sleep durations [23]. Factors such as not separating children from adolescents (as sleep needs change from childhood to adolescence) may have influenced results among the sample of children aged 11-16 years old in Gupta et al. [22]. The restricted length of monitoring in this study (24 hrs) may also not be fully representative of usual behaviour [24]. On top of these, the wear-site of accelerometers has been reported to influence readings, with a validation study reporting that wrist accelerometry data tends to significantly over estimate children's PA and underestimate ST [20].

As Australian studies investigating the relationship between children's sleep, weight status PA and SB have been cross-sectional in nature and reliant on subjective measures [17, 25-27], the use of hip worn accelerometry to objectively measure children's PA and SB would strengthen our understanding of the association between sleep and these factors among Australian children [17, 25-27].

In this study we determine the relationship between PA, ST and weight status on sleep duration, among a sample of Victorian Primary School children, using objective measures of PA and ST.

In this paper it is hypothesised that, compared with sufficient sleepers, children with insufficient sleep durations will more likely be overweight or obese and record lower average daily PA and higher average daily ST. It is also hypothesised that environmental factors around increased screen behaviours (the number of TVs per house and having a TV or electronic gaming device in the bedroom) will significantly reduce children's sleep duration.

\section{Methods}

This study utilised a sub-sample of cross-sectional data on grades four and six primary school children from a pilot study (2013), of a state-based cluster randomised control trial, the methods of which have previously been published (Strugnell et al., under review).

A random sample of 156 primary schools were invited to participate, of which 39 consented (school-level response rate $(R R)=25 \%)$. All grades four and six students within these schools were then invited to participate and provided with plain language statements and consent forms. This pilot study used opt-in consent, where participation required a parent/guardian signed consent form. Of the 2,357 invited, 839 students returned the consent form, enabling their participation (student-level $\mathrm{RR}=35.6 \%$ ). In order to analyse objectively measured PA and ST, only data from a sub-sample of students who were provided with an accelerometer $(\mathrm{N}=373)$ was used.

\section{Measures \\ Anthropometric measures}

Trained data collectors collected measurements on children's height (HM200P Stadiometer, Charder Electronic Co, Ltd), weight (UC-321 scale, A\&D Australasia Pty Ltd) and waist circumference (WC) (Lufkin W606PM metal tape measure, Apex Tool Group, LLC), following the procedure previously published [28]. Children's measurements were taken wearing one layer of light clothing (e.g. t-shirt and pants) with shoes and jumpers removed. All measurements were taken twice, to the nearest $0.1 \mathrm{~cm}$ for height and waist and the nearest $0.01 \mathrm{~kg}$ for weight, with a third measurement required for any discrepancies greater than $0.5 \mathrm{~cm}$ or $0.5 \mathrm{~kg}$. The mean height and weight measurements were used to generate BMI-z scores according to the WHO international BMI growth reference standards [29].

\section{Sleep duration}

Children were asked "During the past 7 days, how much time did you usually spend sleeping per night?" and then selected one of the nine options ("less than 5 hours", "5 hours" "6 hours", "7 hours", "8 hours", "9 hours" "10 hours", "11 hours", or "more than 12 hours"). Aligning with recommendations by the Australian Sleep Health Foundation [12] and classifications used in previous literature [17, 30,31], sufficient sleep was categorised as 10 or more hours of sleep per night and less than this as insufficient sleep.

\section{Physical activity and sedentary time}

Every second student across genders and grade levels (e.g. $1^{\text {st }}, 3^{\text {rd }}, 5^{\text {th }}$ for boys and girls in Grade 6 etc.) were invited to wear a waist-worn ActiGraph GT3X or GT3X+ accelerometer (ActiGraph, Pensacola, FL) to collect objectively measured data on daily PA and ST. Participants were instructed to wear the monitor on the right hip 
during waking hours for seven days, except during waterbased or high contact activities (e.g. martial arts).

To reduce the possibility for any discrepancies between ActiGraph models they were both programed with a 15-second epoch and a 30-hertz sampling rate [32]. A valid day was considered if $\geq 600$ minutes per day (mins. $\mathrm{d}^{-1}$ ) of wear time was recorded, according to the criteria of wear/non-wear time by Troiano and colleagues (2008) [33], over a minimum of three days. Average daily moderate to vigorous physical activity (MVPA), light intensity physical activity (LPA) and ST were determined by summing the time spent in each category according to 3-axial activity count cut-points developed for children aged 10-15 years [34]. Using the average day method outlined by Olds (2007) [35] total average MVPA time was dichotomised according to the Australian PA guidelines for children, into an average of $\geq 60 \mathrm{~min} /$ day (guidelines met) or an average of $<60 \mathrm{~min} /$ day (guidelines not met) [36, 37], allowing for categorical analysis of children's PA. As there are currently no specific daily ST guidelines (except for the restriction of screen time to $2 \mathrm{hrs} /$ day) or daily LPA [38, 39], low, moderate and high tertiles were created to enable categorical comparison of these variables with sleep duration.

\section{Demographic variables}

Demographic items included age, gender and whether English was the only language spoken at home.

\section{Confounding variables}

Participants were asked to report on environmental factors surrounding sedentary behaviours, the presence of a $\mathrm{TV}$ in the bedroom (Yes/No) as well as having an electronic gaming device (EGD) or laptop/computer in the bedroom (Yes/No). Clustering by Local Government Areas was included to account for the sampling design.

\section{Statistical analysis}

STATA SE12 (Stata Corporation, Texas, USA) was used for all statistical analysis. Aligned with recommendations from previous studies $[16,24,40-41]$, only participants with $\geq 3$ days of accelerometry wear-time data were included for analysis $(\mathrm{N}=298 ; 80 \%$ of possible participants). Parametric tests for normality were conducted on all independent variables, resulting in participants with values $\pm 3 S D$ from the mean on independent variables of MVPA, LPA, ST, BMI, and WC being omitted from the relevant analysis $(n=9)$.

Chi-squared and paired t-tests were used to assess gender differences for each variable. Chi-square tests were conducted to assess potential differences between insufficient and sufficient sleep duration and weight status, LPA, MVPA and ST, using the categorical expression of each variable. Lastly, multivariate hierarchical logistic regression analyses were used to calculate the effect of sleep duration on weight status after adjusting for hypothesised covariates including age, gender, SocioEconomic Indexes for Areas (SEIFA), PA, ST, TV in bedroom and computer/EGD in the bedroom.

\section{Results}

Of the 289 participants (56\% girls; $54.3 \%$ grade four) with valid accelerometer data $30.5 \%$ were categorised as overweight or obese (36.2\% boys, $25.9 \%$ girls), $87 \%$ came from English speaking homes and $52.5 \%$ lived in areas categorised as being in the lower two SEIFA quintiles (Table 1).

A third (33.2 \%) of all participants were classified as receiving insufficient sleep, with no significant gender differences $\left(x^{2}=9.68, p=0.84\right)$. Of those categorised as insufficient sleepers, $39.6 \%$ were also classified as either overweight $(25.0 \%)$ or obese $(14.6 \%)$. This proportion was significantly greater than the proportion of sufficient sleepers categorised as overweight or obese $\left(25.9 \% ; x^{2}=\right.$ 5.66, $\mathrm{p}=0.02$ ).

No significant difference was found $\left(\mathrm{x}^{2}=3.46, \mathrm{p}=0.12\right.$; and $\mathrm{x}^{2}=2.21, \mathrm{p}=0.33$, respectively) between the proportion of children categorised as overweight or obese with or without accelerometry data, or between participants with valid or invalid accelerometry wear-time. However, sleep categorisation was found to differ significantly between the excluded participants and analysed sample $\left(x^{2}=9.72, p=0.00\right)$, with the current sample displaying an under-representation of overweight/obese insufficient sleeper (13\%) compared to non-analysed (16\%).

A multivariate hierarchical logistic regression (Model 1; Table 2) shows that insufficient sleepers were more likely to be in the overweight range (OR 1.72; $95 \% \mathrm{CI}: 1.10-2.68$ ) compared to the normal weight range but no such association was observed for those in the obese range (OR 1.80; $95 \%$ CI:0.94-3.45). Adjustment of the initial model for age, gender, SEIFA and study condition (Model 2; Table 2) shows insufficient sleepers more likely to be categorised as overweight (OR 1.88; 95 \% CI:1.14-3.13) or obese (OR $2.31 ; 95 \% \mathrm{CI}: 1.18-4.53)$. Of the demographic variables only age was related to sleep duration (OR 1.59; $95 \%$ CI:1.17-2.16:). Model 3 shows that after further adjustment for environmental characteristics the relationship between weight status and sleep remains significant (overweight OR 1.97; 95 \% CI:1.11-3.48 and obese OR 2.43; 95 \% CI:1.26-4.71) as does age (OR 1.57; 95 \% CI:1.152.13). Presence of a computer/EGD in the bedroom was related to sleep duration and insufficient sleepers were twice as likely to have one (or more) of these devices in the bedroom. (OR 2.11; 95 \% CI:1.25-3.59). Across all three models no significant association was found between children's sleep and their MVPA, LPA or ST. 
Table 1 Unadjusted descriptive statistics ${ }^{\S}$

\begin{tabular}{|c|c|c|c|c|}
\hline & & All (N=289) & Boys $(\mathrm{N}=127)$ & Girls $(N=162)$ \\
\hline Age (years) & & $11.2 \pm 1.0$ & $11.3 \pm 1.1$ & $11.1 \pm 1.0$ \\
\hline English sole language at home (\% ) ${ }^{a}$ & & 87.0 & 86.9 & 87.0 \\
\hline \multirow[t]{5}{*}{ SEIFA (\%)* } & $1^{\text {st }}$ Quintile & 24.6 & 31.1 & 19.8 \\
\hline & $2^{\text {nd }}$ Quintile & 27.9 & 27.7 & 28.0 \\
\hline & $3^{\text {rd }}$ Quintile & 12.0 & 8.4 & 14.7 \\
\hline & $4^{\text {th }}$ Quintile & 30.4 & 28.6 & 31.9 \\
\hline & $5^{\text {th }}$ Quintile & 5.1 & 4.2 & 5.7 \\
\hline $\mathrm{BMI}-z^{*}$ & & $0.4 \pm 1.1$ & $0.6 \pm 1.2$ & $0.3 \pm 1.1^{*}$ \\
\hline Overweight/Obese (\% ) ${ }^{\mathrm{b} *}$ & & 30.5 & 36.2 & $25.9^{*}$ \\
\hline$W C(\mathrm{~cm}) * *$ & & $66.1 \pm 8.7$ & $67.6 \pm 9.3$ & $64.9 \pm 8.1^{* *}$ \\
\hline Average no of accelerometer days & & $5.1 \pm 1.3$ & $5.2 \pm 1.3$ & $5.1 \pm 1.3$ \\
\hline Average wear time (min.day-1) & & $786.1 \pm 70.1$ & $784.7 \pm 73.1$ & $787.1 \pm 67.9$ \\
\hline MVPA (min.day-1) ** & & $101.0 \pm 31.0$ & $116.5 \pm 29.2$ & $88.9 \pm 26.7^{* *}$ \\
\hline Precent meeting PA Guidelines (\%) ** & & 91.4 & 96.9 & $87.0^{* *}$ \\
\hline \multirow[t]{4}{*}{ LPA (min.day-1)** } & Total LPA & $196.9 \pm 33.7$ & $191.4 \pm 28.8$ & $201.1 \pm 36.6^{* *}$ \\
\hline & Low LPA & $160.3 \pm 16.3$ & $163.9 \pm 13.0$ & $155.9 \pm 18.9$ \\
\hline & Med LPA & $196.3 \pm 8.2$ & $196.6 \pm 8.4$ & $196.1 \pm 8.0$ \\
\hline & High LPA & $233.9 \pm 19.2$ & $220.1 \pm 12.5$ & $236.4 \pm 21.6$ \\
\hline \multirow[t]{4}{*}{ ST $(\min$. day -1$) *$} & Total ST & $487.2 \pm 81.2$ & $475.9 \pm 83.4$ & $496.1 \pm 78.6^{*}$ \\
\hline & Low ST & $406.8 \pm 36.9$ & $396.2 \pm 40.8$ & $416.7 \pm 29.8$ \\
\hline & Med ST & $481.9 \pm 15.3$ & $480.6 \pm 16.3$ & $482.9 \pm 14.6$ \\
\hline & High ST & $578.4 \pm 59.5$ & $574.1 \pm 58.7$ & $581.3 \pm 60.4$ \\
\hline \multirow[t]{9}{*}{ Sleep Duration (\%) } & $<5$ & 2.1 & 3.1 & 1.2 \\
\hline & 5 & 1.0 & 0.8 & 1.2 \\
\hline & 6 & 2.8 & 3.9 & 1.9 \\
\hline & 7 & 3.1 & 3.1 & 3.1 \\
\hline & 8 & 7.3 & 7.9 & 6.8 \\
\hline & 9 & 17.0 & 15.0 & 18.5 \\
\hline & 10 & 38.0 & 41.7 & 35.2 \\
\hline & 11 & 18.7 & 12.6 & 23.5 \\
\hline & $\geq 12$ & 10.0 & 11.8 & 8.6 \\
\hline \multicolumn{5}{|l|}{ Sleep Category (\%) } \\
\hline Insufficient (<10hrs/night) & & 33.2 & 33.9 & 32.7 \\
\hline Sufficient ( $\geq 10 \mathrm{hrs} /$ night) & & 66.8 & 66.1 & 67.3 \\
\hline TV in bedroom (\%) ${ }^{a}$ & & 31.8 & 33.1 & 30.9 \\
\hline \multirow[t]{3}{*}{ Number of TVsin house (\%) } & $<2$ & 40.8 & 36.2 & 44.4 \\
\hline & $3-4$ & 40.5 & 43.3 & 38.3 \\
\hline & $\geq 5$ & 18.7 & 20.5 & 17.3 \\
\hline Computer/Elec. gamesin bedroom(\%) ${ }^{a} *$ & & 39.3 & 45.2 & $34.8^{*}$ \\
\hline
\end{tabular}

$\S \pm 3$ SD on BMI, waist, ST, MVPA and LPA excluded

a Divergent number of participants: English sole language at home: $\mathrm{N}=122$ for boys; TV in bedroom: $\mathrm{N}=124$ for boys; Computer/Elec. Games in bedroom: $\mathrm{N}=124$ for boys and $\mathrm{N}=161$ for girls

${ }^{b}$ defined by WHO World Health Organization. (1)

${ }^{*} p<0.05$ for sex difference; ${ }^{* *} p<0.01$ for sex difference

SEIFA - Socio-Economic Indexes for Areas; WC-waist circumference; MVPA-moderate to vigorous physical activity; LPA-low intensity physical activity; ST- sedentary time 1. World Health Organization. WHO Child Growth Standards: Length/height-for-age, weight-for-age, weight-for-length, weight-for-height and body mass index-forage, Methods and development. 2006 
Table 2 Multiple logistic regression: with odds ratios according to sleep category (sufficient vs. insufficient)

\begin{tabular}{|c|c|c|c|c|c|c|}
\hline \multirow[t]{2}{*}{ Variable } & \multicolumn{2}{|c|}{ Model 1} & \multicolumn{2}{|c|}{ Model 2} & \multicolumn{2}{|l|}{ Model 3} \\
\hline & $\mathrm{OR}$ & $95 \% \mathrm{Cl}$ & OR & $95 \% \mathrm{Cl}$ & $\mathrm{OR}$ & $95 \% \mathrm{Cl}$ \\
\hline \multicolumn{7}{|l|}{ Weight Status } \\
\hline Overweight & $1.720^{*}$ & $1.103-2.681$ & $1.888^{*}$ & $1.138-3.131$ & $1.968^{*}$ & $1.112-3.481$ \\
\hline Obese & 1.800 & $0.940-3.446$ & $2.306^{*}$ & $1.175-4.526$ & $2.433^{* *}$ & $1.256-4.711$ \\
\hline \multicolumn{7}{|l|}{ Activity Levels } \\
\hline MVPA & 1.002 & $0.991-1.014$ & 1.003 & 0.990-1.016 & 1.003 & $0.991-1.015$ \\
\hline LPA & 0.999 & 0.990-1.009 & 1.001 & $0.992-1.010$ & 1.001 & $0.992-1.010$ \\
\hline ST & 1.003 & $0.999-1.006$ & 1.002 & $0.999-1.005$ & 1.002 & $0.999-1.004$ \\
\hline \multicolumn{7}{|l|}{ Demographic } \\
\hline Age (Years) & & & $1.593 * *$ & $1.174-2.162$ & $1.565^{* *}$ & $1.150-2.128$ \\
\hline Gender & & & 1.192 & $0.593-2.396$ & 1.276 & $0.666-2.442$ \\
\hline SEIFA & & & 1.036 & $0.854-1.256$ & 1.059 & $0.880-1.275$ \\
\hline Condition & & & 0.829 & $0.460-1.493$ & 0.848 & $0.465-1.546$ \\
\hline \multicolumn{7}{|l|}{ Environmental } \\
\hline TV Room & & & & & 1.100 & $0.574-2.105$ \\
\hline Comp Room & & & & & $2.115^{* *}$ & $1.245-3.593$ \\
\hline
\end{tabular}

Model 1: Unadjusted logistical regression on hypothesised correlated variables; Model 2:Logistical regression, adjusted for demographic covariates (Age, Gender \& SEIFA) and condition; Model 3: Logistical regression, further adjusted for environmental covariates (TV in room \& Computer/EGD in bedroom)

$\mathrm{OR}$ - odds ratio; $\mathrm{Cl}$ - confidence interval; ${ }^{*} \mathrm{p}<0.05 ;{ }^{* *} \mathrm{p}<0.01$;

\section{Discussion}

The hypothesis that children with insufficient sleep are more likely to be categorised as being overweight or obese, less physically active and more sedentary was partly supported. Using objective measures of height and weight we found that weight status was inversely associated with children's self-reported sleep duration. In contrast to previous studies no relationship was observed between PA, ST and sleep duration. However, in the current study age and presence of computer/EGD in the bedroom were inversely associated with children's sleep duration.

In this study, a third of participants were categorised as insufficient sleepers. The high levels of sleep deprivation among the current sample is comparable with that reported by Shi et al. (2010), where $48.2 \%$ of their sample of 3,495 South Australian children (5-15 years) were reported sleeping less than 10 hours per night by their parents [17]. Other estimates of insufficient sleep are higher; a nationally representative sample of 6,324 Australian 7-15 year olds found that almost two-thirds $(62.4 \%)$ reported not getting the recommended $10+$ hours of sleep per night [26]. This may suggest that the national prevalence of sleep deprivation among children could be an even more substantial issue outside of the two states of South Australia and Victoria, or most likely be due to the difference in self-report versus parent-report measures used.

Despite these disparities, the findings about the size and direction for the relationship between sleep and children's weight status found in this study are consistent among local and international studies such as those by Shi et al. (2010) and Seegers et al. (2011) [17, 42]. Our results suggest that children reporting insufficient sleep were almost twice as likely to be overweight and almost two and a half times more likely to be obese than those meeting sleep duration recommendations. Our study supports international findings from 1,916 10-13 year olds in Quebec showing insufficient or shorter sleep durations among children increased the odds of being obese by 1.41 (95 \% CI:1.24, 1.61) times [42].

As several national sleep guidelines have been extended recently, suggesting nine and potentially eight hours of sleep per night might be sufficient for some children [12,43], additional analyses were conducted to explore how adjusting the categorization of insufficient sleep influences results among the current sample. While our initial analysis indicated sleeping $\leq 9$ hours per night was shown to increase the odds of overweight and obesity compared with sleeping $\geq 10$ hours, when recategorising insufficient sleep as $\leq 8$ or $\leq 7$ hours of sleep per night no significant association was found. However, the reduced power due to the low representation of participants in these categories (only $16 \%$ sleeping $\leq 8$ hours per night and only $9 \%$ sleeping $\leq 7$ hours) makes it difficult to assume that these cut-points would not reach significance among larger samples. This highlights the importance to consider the cut-points being used to determine sufficient sleep in future studies, as well as the need for larger more representative samples. 
We found no relationship between children's sleep duration and average MVPA, LPA and ST, which contrast findings from previous studies $[9,16,17,21]$. The lack of association between these factors in the current study could be due to a number of reasons including: the differentiation between previous subjectively measured PA and ST compared with the current objective accelerometry data; the slightly smaller sample size due to the restriction of available accelerometers; or due to characteristics surrounding the type of participants who adhered to wear-time requirements and therefore were included in the analysis.

There has been some indication that participants with higher BMI, waist circumference and sedentary behaviours may be less likely to meet wear-time requirements [44]. In such cases, results may not fully represent the study population and may have produced an overestimation of the sample population's PA and underrepresentation of average ST [44]. However, our analysis does not support this suggesting no significant weight status differences between children with valid versus invalid accelerometry wear-time, or between participants with or without accelerometry data.

Although we found no significant association between sleep duration and children's ST in the current study, it is interesting to note that having a computer/EGD in the bedroom was associated with children's sleep durations. Children who reported having a computer/gaming console in the bedroom had twice the odds for not receiving the recommended $\geq 10$ hours of sleep per night. One potential explanation for this relationship suggests that sedentary behaviours involving computer/EGD directly deduct from children's sleep duration by interfering with time that should be dedicated to sleeping, but not necessarily influencing their overall average daily ST [45]. It has also been suggested that exposure to artificial light created by these screen behaviours may lead to disruptions in the circadian rhythm, with an increase in alertness and decreased sleep onset and duration [46]. It may be useful for future research to examine the times of day that children engage in screen based activities so that recommendations can be extended to include guidelines around screen-free times in order to promote sufficient sleep.

Another possible explanation for the association between computers/EGDs and insufficient sleep among children may be linked within the significant inverse association between children's sleep and their age, demonstrated in the current and previous studies [17, 21, 47]. While literature suggests this age associated decline in sleep duration could be related to later bed times of older children without adjusting wake-up times [14, 48], it has been proposed that it might be due the higher usage of electronic devices (such as computers, phones and TVs) in older children/adolescents [9, 21, 47-49].
More work is need to gain a deeper understanding on the modifiers and confounders of the association between children's sleep and weight status. Despite not finding an association between objectively measured average daily PA and ST, our findings of an association between electronic devices such as computers/EGD and reduced sleep duration highlights the need to better understand how these behaviours influence children's sleep. Future studies would also benefit from more stringent measures on sleep duration (such as accelerometers).

\section{Conclusion}

Among this sample of Victorian primary school children sleep duration was inversely associated with weight status, though not between objectively measured PA and ST. Insufficient sleep was significantly higher among children with a computer/EGD in their bedroom. The findings suggest sleep is a plausible target behaviour for obesity prevention initiatives.

\section{Ethics}

Ethics approval was received from the Deakin University's Human Research Ethics Committee, the Victorian Department and Early Childhood Development and the Catholic Education Office Archdiocese's of Melbourne, Sale, Sandhurst and Ballarat for this study.

\section{Abbreviations \\ PA: physical activity; ST: sedentary time; BMI: Body Mass Index; WC: waist circumference; LPA: light intensity physical activity; MVPA: moderate to vigorous physical activity; EGD: electronic gaming device; SEIFA: Socio- Economic Indexes for Areas.}

\section{Competing interests}

The authors confirm they hold no conflict of interest.

\section{Authors' contributions}

BM carried out the development of this manuscript, background research and data analysis. CS, MM and JW participated in drafting and editing the manuscript. SA, BS, CS, LM and MM were involved in the study design, protocols and data collection. All authors were involved in the revising of the manuscript and have read and approved the final version for submission.

\section{Acknowledgements}

Strugnell, Millar and Allender are all members of the executive committee overseeing the design, implementation and evaluation of the present study. Morrissey led the development of the manuscript and all authors were involved in refining the paper and had final approval of the submitted and published versions. Allender is supported by funding from an Australian National Health and Medical Research Council/ Australian National Heart Foundation Career Development Fellowship (APP1045836). Strugnell, Millar, Malakellis, Swinburn and Allender are researchers within a NHMRC Centre for Research Excellence in Obesity Policy and Food Systems (APP1041020). Allender and Swinburn are supported by US National Institutes of Health grant titled Systems Science to Guide Whole-of-Community Childhood Obesity Interventions (1R01HL115485-01A1). Millar is supported by an Alfred Deakin Early Career Research Fellowship. This study was supported by a 2013 Australian National Heart Foundation Vanguard Grant (100259). In addition, we would like to acknowledge the support from the Victorian Department of Health and Human Services and the Victorian Department of Education and Training. 


\section{Author details}

'School of Health and Social Development, Deakin University, 221 Burwood Hwy, Burwood, Victoria 3125, Australia. ${ }^{2}$ World Health Organization's Collaborating Centre for Obesity Prevention, Deakin Population Health, Deakin University, Geelong, Australia. ${ }^{3}$ The CO-OPS Collaboration, WHO-CC, Deakin Population Health, Deakin University, Geelong, Australia. ${ }^{4}$ School of Population Health, The University of Auckland, Auckland, New Zealand.

\section{Received: 23 July 2015 Accepted: 1 March 2016} Published online: 09 March 2016

\section{References}

1. Lobstein T, Baur L, Uauy R. Obesity in children and young people: a crisis in public health. Obesity Reviews. 2004;5:4-85.

2. Han JC, Lawlor DA, Kimm S. Childhood obesity. The Lancet. 2010:375(9727): 1737-48.

3. Prentice-Dunn H, Prentice-Dunn S. Physical activity, sedentary behavior, and childhood obesity: a review of cross-sectional studies. Psychol Health Med. 2012;17(3):255-73.

4. Swinburn BA, Sacks G, Hall KD, McPherson K, Finegood DT, Moodie ML, et al. The global obesity pandemic: shaped by global drivers and local environments. The Lancet. 2011;378(9793):804-14.

5. Tremblay MS, LeBlanc AG, Kho ME, Saunders TJ, Larouche R, Colley RC, et al. Systematic review of sedentary behaviour and health indicators in schoolaged children and youth. Int J Behav Nutr Phys Act. 2011;8(1):98.

6. Connelly JB, Duaso MJ, Butler G. A systematic review of controlled trials of interventions to prevent childhood obesity and overweight: a realistic synthesis of the evidence. Public Health. 2007;121(7):510-7.

7. Doak CM, Visscher TLS, Renders CM, Seidell JC. The prevention of overweight and obesity in children and adolescents: a review of interventions and programmes. Obesity Reviews. 2006;7(1):111-36.

8. Azadbakht L, Kelishadi R, Khodarahmi M, Qorbani M, Heshmat R, Motlagh $M E$, et al. The association of sleep duration and cardiometabolic risk factors in a national sample of children and adolescents: the CASPIAN III study. Nutrition (Burbank, Los Angeles County, Calif). 2013;29(9):1133-41.

9. Hitze B, Bosy-Westphal A, Bielfeldt F, Settler U, Plachta-Danielzik S, Pfeuffer $M$, et al. Determinants and impact of sleep duration in children and adolescents: data of the Kiel Obesity Prevention Study. Eur J Clin Nutr. 2009; 63(6):739-46.

10. Jarrin D, McGrath J, Drake C. Beyond sleep duration: distinct sleep dimensions are associated with obesity in children and adolescents. Int J Obes. 2013;37(4):552-8.

11. U.S National Sleep Foundation. Children and Sleep. Arlington, USA2014. Available from: http://sleepfoundation.org/sleep-topics/children-and-sleep/ page/0\%2C2/

12. Australian Sleep Health Foundation. Sleep needs across a lifespan 2011. Available from: http://www.sleephealthfoundation.org.au/fact-sheets-a-z/ 230-sleep-needs-across-the-lifespan.html

13. Matricciani L, Olds T, Petkov J. In search of lost sleep: Secular trends in the sleep time of school-aged children and adolescents. Sleep Medicine Reviews. 2012;16(3):203-11.

14. Dollman J, Ridley K, Olds T, Lowe E. Trends in the duration of school-day sleep among 10- to 15-year-old South Australians between 1985 and 2004 Acta Paediatrica. 2007;96(7):1011-4.

15. Cappuccio FP, Taggart FM, Kandala NB, Currie A, Peile E, Stranges S, et al. Meta-analysis of short sleep duration and obesity in children and adults. Sleep. 2008;31(5):619-26.

16. Garaulet M, Ortega FB, Ruiz JR, Rey-López JP, Béghin L, Manios Y, et al. Short sleep duration is associated with increased obesity markers in European adolescents: effect of physical activity and dietary habits. The HELENA study. Int J Obes. 2011;35(10):1308-17.

17. Shi Z, Taylor AW, Gill TK, Tuckerman J, Adams R, Martin J. Short sleep duration and obesity among Australian children. BMC Public Health. 2010; 10:609.

18. Snell EK, Adam EK, Duncan GJ. Sleep and the body mass index and overweight status of children and adolescents. Child development. 2007; 78(1):309-23.

19. Wells JC, Hallal PC, Reichert FF, Menezes AM, Araujo CL, Victora CG. Sleep patterns and television viewing in relation to obesity and blood pressure: evidence from an adolescent Brazilian birth cohort. Int J Obes. 2008; 32(7):1042-9.
20. Brooke HL, Corder K, Atkin AJ, van Sluijs EM. A systematic literature review with meta-analyses of within-and between-day differences in objectively measured physical activity in school-aged children. Sports Medicine. 2014; 44(10):1427-38

21. Ekstedt M, Nyberg G, Ingre M, Ekblom Ö, Marcus C. Sleep, physical activity and BMI in six to tenyear- old children measured by accelerometry: a crosssectional study. Int J Behav Nutrition Phys Act. 2013;10(1):82-91.

22. Gupta NK, Mueller WH, Chan W, Meininger JC. Is obesity associated with poor sleep quality in adolescents? Am J Hum Biol. 2002;14(6):762-8.

23. Nixon GM, Thompson JMD, Han DY, Becroft DM, Clark PM, Robinson E, et al. Short sleep duration in middle childhood: Risk factors and consequences. Sleep. 2008;31(1):71-8.

24. Trost SG, Mclver KL, Pate RR. Conducting accelerometer-based activity assessments in field-based research. Med Sci Sports Exerc. 2005;37(11):531-43.

25. Olds T, Blunden S, Dollman J, Maher CA. Day type and the relationship between weight status and sleep duration in children and adolescents. Aust N Z J Public Health. 2010;34(2):165-71.

26. Eisenmann JC, Ekkekakis P, Holmes M. Sleep duration and overweight among Australian children and adolescents. Acta Paediatr. 2006;95(8):956-63.

27. Morley BC, Scully ML, Niven PH, Okely AD, Baur LA, Pratt IS, et al. What factors are associated with excess body weight in Australian secondary school students? Med J Aust. 2012;196(3):189-92.

28. (CSIRO) CSlaRO. User Guide: 2007 Australian National Children's Nutrition and Physical Activity Survey. University of South Australia, 2007.

29. de Onis M, Onyango AW, Borghi E, Siyam A, Nishida C, Siekmann J. Development of a WHO growth reference for school-aged children and adolescents. Bull World Health Organ. 2007;85(9):660-7.

30. Altenburg TM, Chinapaw MJ, van der Knaap ET, Brug J, Manios Y, Singh AS. Longer Sleep-Slimmer Kids: The ENERGY-Project. PloS one. 2013:8(3), e59522.

31. Au CT, Ho CKW, Wing YK, Lam HS, Li AM. Acute and chronic effects of sleep duration on blood pressure. Pediatrics. 2014;133(1):e64-72.

32. Robusto KM, Trost SG. Comparison of three generations of ActiGraph ${ }^{\text {TM }}$ activity monitors in children and adolescents. J Sports Sci. 2012;30(13):1429-35.

33. Troiano RP, Berrigan D, Dodd KW, Masse LC, Tilert T, McDowell M. Physical activity in the United States measured by accelerometer. Med Sci Sports Exerc. 2008:40(1):181-8.

34. Romanzini M, Petroski EL, Ohara D, Dourado AC, Reichert FF. Calibration of ActiGraph GT3X, Actical and RT3 accelerometers in adolescents. European Journal of Sport Science. 2012;14(1):91-9.

35. Olds T, Ridley K, Wake M, Hesketh K, Waters E, Patton G, et al. How should activity guidelines for young people be operationalised? Int J Behav Nutrition Phys Act. 2007:4(1):43.

36. The Department of Health. Australia's Physical Activity and Sedentary Behaviour Guidelines Canberra2014b. Available from: http://www.health.gov. au/internet/main/publishing.nsf/Content/health-pubhlth-strateg-phys-actguidelines\#apa1317

37. The Department of Health. Australia's Physical Activity and Sedentary Behaviour Guidelines for Children (5-12 years) 2014a. Available from: http:// www.health.gov.au/internet/main/publishing.nsf/Content/health-pubhlthstrateg-phys-act-guidelines/\$File/FS-Children-5-12-Years.PDF.

38. Saunders TJ, Chaput JP, Tremblay MS. Sedentary behaviour as an emerging risk factor for cardiometabolic diseases in children and youth. Can Diabetes. 2014:38(1):53-61.

39. Tremblay MS, LeBlanc AG, Janssen I, Kho ME, Hicks A, Murumets K, et al. Canadian sedentary behaviour guidelines for children and youth. Appl Physiol Nutr Metab. 2011;36(1):59-64

40. Eston RG, Rowlands AV, Ingledew DK. Validity of heart rate, pedometry, and accelerometry for predicting the energy cost of children's activities. Journal of Applied Physiology. 1998;84(1):362-71.

41. Matthews CE, Chen KY, Freedson PS, Buchowski MS, Beech BM, Pate RR, et al. Amount of Time Spent in Sedentary Behaviors in the United States, 2003-2004. Am J Epidemiol. 2008:167(7):875-81.

42. Seegers V, Petit D, Falissard B, Vitaro F, Tremblay RE, Montplaisir J, et al. Short sleep duration and body mass index: a prospective longitudinal study in preadolescence. Am J Epidemiol. 2011;173(6):621-9.

43. U.S National Sleep Foundation. National Sleep Foundation Recommends New Sleep Times: U.S National Sleep Foundation; 2015. Available from: https://sleepfoundation.org/media-center/press-release/national-sleepfoundation-recommends-new-sleep-times.

44. Loprinzi PD, Smit E, Cardinal BJ, Crespo C, Brodowicz G, Andersen R. Valid and invalid accelerometry data among children and adolescents: 
comparison across demographic, behavioral, and biological variables. Am J Health Promot. 2014;28(3):155-8.

45. Golley RK, Maher C, Matricciani L, Olds T. Sleep duration or bedtime: Exploring the association between sleep timing behaviour, diet and $\mathrm{BMI}$ in children and adolescents. Int J Obes. 2013;37(4):546-51.

46. Cajochen C, Frey S, Anders D, Späti J, Bues M, Pross A, et al. Evening exposure to a light-emitting diodes (LED)-backlit computer screen affects circadian physiology and cognitive performance. J Appl Physiol. 2011;110(5): 1432-8.

47. Kong AP, Wing Y-K, Choi KC, Li AM, Ko GT, Ma RC, et al. Associations of sleep duration with obesity and serum lipid profile in children and adolescents. Sleep medicine. 2011;12(7):659-65.

48. de Jong E, Stocks T, Visscher TLS, HiraSing RA, Seidell JC, Renders CM Association between sleep duration and overweight: the importance of parenting. Int J Obes. 2012;36(10):1278-84

49. Hart CN, Cairns A, Jelalian E. Sleep and obesity in children and Adolescents. Pediatr Clin North Am. 2011:58(3):715-33.

Submit your next manuscript to BioMed Central and we will help you at every step:

- We accept pre-submission inquiries

- Our selector tool helps you to find the most relevant journal

- We provide round the clock customer support

- Convenient online submission

- Thorough peer review

- Inclusion in PubMed and all major indexing services

- Maximum visibility for your research

Submit your manuscript at www.biomedcentral.com/submit
) Biomed Central 